\title{
ECONOMIC THEORY
}

\author{
AND THE \\ SPATIAL MISMATCH HYPOTHESIS
}

\author{
Richard Arnott*
}

September 1997

Acknowledgments: The inspiration for this paper was a conversation with John Kain in which he encouraged me to write a theoretical paper strengthening the microfoundations of the spatial mismatch hypothesis. An earlier version of this paper was presented at the 1996 TRED Conference on "Transportation and Land Use." I am grateful to the participants and especially my discussant Vernon Henderson for helpful comments and criticisms. I would also like to thank Sanche Llewellyn and Michael Hansen, two Boston College Ph.D. students, whose term essays on the topic stimulated my thinking, Alexander Kalenik and An Yan for research assistance, seminar participants at Boston College for insightful comments, and the editor and two referees for helpful comments on an earlier draft.

Sadly, I associate this paper with Bill Vickrey's death since Bill died en route to the TRED Conference at which I presented the original version of the paper. I would therefore like to dedicate this paper to his memory.

\footnotetext{
* Department of Economics Boston College Chestnut Hill, MA 02167 U.S.A.
} 


\section{Economic Theory and the Spatial Mismatch Hypothesis}

\section{Introduction}

The spatial mismatch hypothesis was first articulated by John Kain in 1964 (Kain, 1994). Kain's seminal paper (Kain, 1968), "Housing Segregation, Negro Employment, and Metropolitan Decentralization," provided the first statement and empirical investigation of the hypothesis. Since then there has been a wealth of empirical studies which focus on the hypothesis or relate to some aspect of it; ${ }^{1}$ Kain's recent review paper (Kain, 1994), "The Spatial Mismatch Hypothesis: Three Decades Later," contains almost two hundred items in its bibliography. In that article, Kain states the hypothesis as follows (p. 371):

Serious limitations on black residential choice, combined with the steady dispersal of jobs from central cities, are responsible for the low rates of employment and low earnings of Afro-American workers.

There is little dispute about the empirical basis of the hypothesis: that there are, or at least have been, serious limitations on black residential choice; that there has been a steady dispersal of jobs from central cities; and that rates of employment and earnings of AfroAmerican workers are relatively low. ${ }^{2}$ Thus, the essence of the hypothesis is causal - that the combination of job suburbanization and housing discrimination has worsened the labor market situation for blacks. One can distinguish between strong and weak forms of the hypothesis, depending on how "are responsible for" is interpreted. The strong form is that "serious limitations on black residential choice, combined with the steady dispersal of jobs from central cities" is the only, or at least paramount, factor causing "the low rates of employment and low earnings of Afro-American workers." The weak form is that "serious . . cities" contributes to "the ... workers." Furthermore, the hypothesis indicates that it is the combination of "serious limitations on black residential choice" and "the steady dispersal of jobs from central cities"

\footnotetext{
${ }^{1}$ I shall not attempt to review this empirical literature. For this, see Kain (1994).

${ }^{2}$ How the spatial mismatch hypothesis should be modified to account for Hispanics and other immigrant groups is an interesting issue, but is beyond the scope of this paper.
} 
November 8, 1997

that causes "the ... workers", rather than either factor in isolation.

The literature on the spatial mismatch hypothesis has identified two broad channels through which the combination of housing discrimination and job suburbanization might adversely affect the labor market situation of blacks. The first is commuting costs (e.g., Ihlanfeldt and Sjoquist (1989, 1990, 1991), Jencks and Mayer (1989)). If blacks are forced to live downtown and jobs are suburbanizing, either more blacks have to commute to jobs in the suburbs or the black unemployment rate has to increase or both. Commuting costs may be substantial because public transportation to most suburban locations is so poor: ${ }^{3}$ the density of service is low; service is infrequent and unreliable; and transfers are frequently required, which increases not only average commuting time but also the variability of commuting time. The second channel is job search (e.g. Holzer (1987, 1988), O'Regan and Quigley (1993, 1996, 1997), Holzer, Ihlanfeldt, and Sjoquist (1994)) which has three aspects: the difficulty a downtown resident encounters in obtaining information on suburban jobs, which is more severe the more prevalent is word-of-mouth advertising; the possible importance of acquaintanceship and connections in obtaining a job; and the high transport and time costs of searching for a suburban job from a downtown residence. ${ }^{4}$ No doubt both channels are operative. But there is disagreement concerning how quantitatively important each is.

I have always had difficulty "understanding" the hypothesis, though I do acknowledge its intuitive appeal. It strikes me as being incomplete. Lurking behind the hypothesis is some conception of how urban housing and labor markets work, and how their operation is affected by housing discrimination and job suburbanization. But the conception is unclear. It is certainly not the case that job suburbanization necessarily hurts downtown residents. For one thing, if more downtown residents commute to work in the suburbs, the capital-labor and landlabor ratios in downtown production rise, which ceteris paribus causes an increase in the downtown wage rate. For another, the suburbanization of jobs causes the derived demand for

\footnotetext{
${ }^{3}$ This argument needs to be enriched to account for possible car ownership.

${ }^{4} \mathrm{~A}$ more recent line of argument is that there are neighborhood peer group effects with respect to attitudes towards work, welfare, and criminal activity (e.g., Sah (1991)).
} 
November 8, 1997

downtown land in production to fall, which causes land rents and hence housing rents to fall. Thus, the causality underlying the hypothesis is incomplete.

Another difficulty with the hypothesis is that the suburbanization of jobs is not an exogenous factor. 5 How the suburbanization of jobs affects downtown black residents depends on what is causing the suburbanization of jobs. This can be illustrated by contrasting two models. The first is an informal "flight from blight" model in which jobs follow people. Suppose that low-income residents generate negative externalities (fiscal externalities, negative peer-group effects in school, etc.) Start off in a situation where everyone lives on one island - downtown. Suppose too that wealthier households are willing to pay more, in the form of commuting costs (and with exclusionary zoning, lot rents), to avoid the negative externalities. Then the movement of the wealthiest household to another island - suburbia - can trigger a process of cumulative causation in which increasingly less rich households "flee" to the suburbs, with jobs following and life downtown becoming increasingly mean. ${ }^{6}$ If blacks are forced to remain downtown due to housing discrimination, their utility falls as jobs suburbanize. The suburbanization of jobs is not, however, causing the fall in utility of downtown residents but is part of the same process. The second model describes a small city with a fixed population that exports a good at a fixed delivered price. The city is again on two islands. Now suppose, due to the construction of the interstate highway system, that the cost of shipping the export good from suburbia falls. It is easy to fill in the details of the model such that the transport improvement causes jobs to suburbanize and makes all residents better off.

These difficulties derive from incompleteness of the conceptualization underlying the hypothesis, and all can be addressed by providing complete conceptualizations. Economists' "complete conceptualizations" are general equilibrium models, which take into account all interdependencies, at least for the abstract world of the model. It is indeed remarkable that,

\footnotetext{
${ }^{5}$ It is, of course, difficult to draw the line between what is endogenous and what exogenous. In commenting on an earlier version of the paper, John Yinger argued that racial attitudes too should be regarded as being endogenous. 6Bénabou (1996) presents a model along these lines.
} 
November 8, 1997

except for recent papers by Brueckner and Martin (1995) and Coulson et al. (1997), the voluminous literature on the spatial mismatch hypothesis includes no theoretical work. But we have the tools to develop relevant models, and it is time we tried. For one thing, there has been virtually no theoretical work on the spatial aspects of urban labor markets ${ }^{7}$; this is certainly a subject area that can be addressed by joining existing models.

The spatial mismatch hypothesis has had considerable impact in policy circles. Using it as a basis, many policy analysts have argued for improved public transportation to make suburban jobs more accessible to downtown blacks, or for assistance to downtown blacks in their search for suburban jobs, typically by improving the availability downtown of information on suburban job vacancies. Both policy proposals have intuitive appeal, but neither is based on any clear articulation of market failure. And if there is no market failure, then, according to the standard economic line of reasoning, the presumed adverse distributional impacts of job suburbanization combined with housing discrimination should be dealt with via redistributive policy. This points to another problem with the spatial mismatch hypothesis. Because its conceptualization is incomplete, no policy implications can logically be drawn from it. This can be remedied by providing a general equilibrium model of the economy and a normative framework, which together can be employed to evaluate the welfare effects of alternative policy interventions. The hypothesis has also had considerable impact in the academic community, especially among academic economists. The reason is that the hypothesis provides really the only attempt ${ }^{8}$ to come to grips with a complex nexus of issues — housing discrimination, crime, welfare dependence, racial problems, and urban labor markets - that urban economists sense is very important.

Before concluding this introduction, let me raise a couple of other points that are important though tangential to the main theme.

\footnotetext{
7 Since this paper was first drafted, several papers have in fact been written, the Brueckner and Martin (1995) and Coulson et al. (1997) papers mentioned previously, and also Zenou and Smith (1995), Wasman and Zenou (1997), and Smith and Zenou (1997).

${ }^{8}$ The literature on mortgage discrimination has addressed some of the issues relating to the deteriorating economic status of blacks.
} 
November 8, 1997

First, it is important to distinguish between spatial mismatch deriving from housing discrimination against blacks and that deriving from segregation by income. According to Mills' (1972) interpretation of the monocentric city model applied to U.S. cities, the poor live downtown because their bid-rent curves are steeper. If this pattern of location is preserved when jobs suburbanize, then there is spatial mismatch between jobs and poor households. It may be, even though poor blacks and poor whites live in segregated neighborhoods downtown, that poor whites are as spatially mismatched as poor blacks.

Second, the spatial mismatch hypothesis seems to be predicated on the notion of a downtown where the majority of blacks live, surrounded by a homogeneous, white suburban fringe. But the pattern of residential location by income and race has become more complex in the years since the spatial mismatch hypothesis was originally formulated, and is becoming increasingly complex. How should the hypothesis be adapted to reflect these changes?

Third, the spatial mismatch hypothesis states that housing discrimination coupled with the suburbanization of jobs has caused the rate of unemployment of downtown blacks to increase. This component of the hypothesis merits elaboration. In particular, the hypothesis needs to identify why these factors together generate a rise in unemployment rather than simply a fall in the wage. Is it because the minimum wage generates involuntary unemployment, because welfare dependence and criminal activity are substitutes for employment, or because, for some reason, the natural rate of unemployment is higher downtown?

Fourth, while not always stated explicitly, the hypothesis appears to focus on unskilled blacks in the central city. What, if anything, does it intend to say about the effects of job suburbanization on educated black workers?

Problems within the black community and concerning the relations between the black community and the rest of society are among the most important and difficult confronting U.S. society. If we are to solve these problems, we must untangle the skein of causality. And to do this, we must proceed scientifically, constructing competing models and testing one versus the 
November 8, 1997

other. General equilibrium models are particularly promising because, by their nature, they take into account all interdependencies - at least for the abstract world the model portrays.

I have been critical of the spatial mismatch hypothesis for its conceptual incompleteness. But conceptual incompleteness is better than no concept at all. The hypothesis is to be credited with providing a focal point for research relating to the interaction between urban housing markets, urban labor markets, and race. We have the tools at hand, however, to construct conceptually complete models and thereby to raise the level of analysis. We should use them.

The primary aim of this paper is methodological — to show how one ${ }^{9}$ of many possible general equilibrium models of the spatial mismatch hypothesis is constructed and to illustrate how the model works. The model was designed with two principal desiderata in mind. The first is that the model be consistent with the original (informal) formulation of the hypothesis, which emphasized commuting costs rather than job search. ${ }^{10}$ The second is that it be rich enough to treat many of the factors that have been advanced to explain the suburbanization of jobs or the immiserization of black workers or both.

\section{The Model}

I start by listing the assumptions of the model and explaining why each was chosen, then present the equations describing the model, and finally explore some of the model's properties.

\section{II.1 Assumptions}

- A.1 (spatial structure) The urban economy consists of two islands, downtown $(i=1)$ and $\operatorname{suburbia}(i=2)$.

This is the simplest way of describing urban spatial structure consistent with the spatial

\footnotetext{
${ }^{9}$ An earlier version of the paper (Arnott (1996)) examined a series of models.

10 This is not because I judge commuting costs to be the more important channel through which housing discrimination along with job suburbanization adversely affects the labor market situation of blacks; indeed, the recent empirical literature (e.g., Holzer, Ihlanfeldt, and Sjoquist (1994) and O'Regan and Quigley (1996, 1997)) suggests that job search is the more important channel.
} 
November 8, 1997

mismatch hypothesis.

- A.2 (commuting costs) Intra-island commuting costs are zero. Inter-island commuting costs are a proportion 1- $\beta$ of a worker's wage.

This provides a simple way of describing commuting costs consistent with the hypothesis. It assumes, unrealistically, that transport costs are exclusively money costs. But to incorporate the time costs of travel would complicate the model without adding anything essential.

Empirical studies suggest that the time costs of travel are more important than money costs, and that the shadow value of travel time is approximately a fixed fraction of the wage. Thus, it is reasonable to assume that commuting costs are a fixed proportion of the wage.

- A.3 (housing discrimination) Blacks are forced to live downtown.

In his discussion of the model, Vernon Henderson aptly termed this the "apartheid" assumption because the residential location of blacks is taken as exogenous. ${ }^{11}$ This assumption was chosen because it greatly simplifies the analysis and because general truths are often most starkly illustrated in models with extreme assumptions. The assumption does, however, come at a cost. For one thing, it does violence to reality; that housing discrimination against blacks lingers on is well-documented (Yinger (1986), Turner (1992)) but it is more subtle and less severe than a generation ago. For another, it precludes analysis of how changes in the degree of segregation or in the intensity of preferences concerning neighborhood racial composition affect spatial mismatch. ${ }^{12}$ Whites may live where they choose, but in the variant of the model to be considered they all choose to live in suburbia. Thus, there is complete segregation in housing.

- A.4 (no labor market discrimination) There is no discrimination in the labor market.

This is not conceptually inconsistent with discrimination in housing markets ${ }^{13}$ but its realism is

\footnotetext{
11 Under apartheid, however, blacks were constrained to live in particular suburban locations.

12 The spatial mismatch hypothesis may be interpreted as saying either that blacks are worse off the more suburbanized are jobs, holding constant limitations on black residential choice, or that blacks are worse off the stricter are limitations on black residential choice, holding constant the degree of job suburbanization. Taking black residential location as given precludes examination of the latter interpretation of the hypothesis. I am grateful to John Yinger for this observation.

${ }^{13}$ Recall Gary Becker's argument (1971) that a competitive firm which discriminates in the labor market will be
} 
November 8, 1997

certainly open to question.

- A.5 (constant returns to scale) Production exhibits constant returns to scale.

This is not an innocuous assumption but greatly simplifies the analysis. ${ }^{14}$

- A.6 (competition) Domestic firms are competitive.

More specifically, domestic firms are price takers rather than price setters. Prices adjust to clear markets. Assumptions 5 and 6 together imply that the prices of domestically-produced goods equal the corresponding unit costs.

The most difficult modeling choices concern the structure of domestic production, the properties of trade in goods between the two islands and between each island and the rest of the world — including the cost of transporting goods — and the use of land. The model should permit analysis of those exogenous factors that have been put forward to explain either the post-World-War-II suburbanization of jobs or the deteriorating labor market situation of blacks. These include: ${ }^{15}$

i) reduction in the cost of shipping between the rest of the world and suburbia compared to downtown, due to the shift from downtown-based ship and rail transport to suburban-based truck transport

ii) the switch in the U.S. economy from manufacturing to services

iii) skilled-labor-augmenting technical change, most notably computerization and improvements in telecommunications

iv) technical change in the production of skill-intensive goods

v) the lowering of international trade barriers and the consequent reduction in the price of unskilled-labor-intensive goods

vi) immigration of unskilled labor.

Distinguishing between skilled and unskilled labor is important, both to permit

forced out of business since non-discriminating firms will be able to sell the product at a lower break-even price.

${ }^{14}$ For example, if there are agglomerative economies of scale (Chipman (1970), Henderson (1988), Krugman (1991)), external to the firm but internal to the island, the suburbanization of jobs will increase productivity in suburbia and lower it downtown, providing a stimulus for further suburbanization.

${ }^{15}$ See Bound and Freeman (1992), Bound and Holzer (1991), Castells (1985), Kasarda (1989). 
November 8, 1997

treatment of the exogenous factors listed above and (as noted in the introduction) to distinguish spatial mismatch of the poor from spatial mismatch of blacks. Since models with three or more factors are considerably more complex than models with two factors, it is assumed that:

- A.7 (factors of production) Domestic firms employ two factors of production, skilled and unskilled labor.

Since domestic production does not therefore use land, all domestic land is used for housing.

It is also assumed that:

- A.8 (skill composition) The ratio of skilled to unskilled workers is higher for whites than for blacks and

- A.9 (downtown crowding) Downtown land area per black worker is significantly lower than suburban land area per white worker.

This assumption captures the idea that housing discrimination against blacks causes not only segregation but also the crowding of blacks.

Assumptions are needed concerning the number of domestically-produced goods and their transportability. Models with one domestically-produced good are too simple to treat many of the exogenous changes listed above, even when augmented to incorporate trade with the rest of the world. Consider models with two domestically-produced goods.

It is a well-known result from trade theory (Caves and Jones (1977)) that: with a common technology, two "regions" (here, downtown and suburbia), two goods that can be transported between the two regions at zero cost, and two factors (here, skilled and unskilled labor), and in the absence of specialization in production, factor price equalization will occur. The proof is straightforward. Because goods are freely transportable, each good has the same price in both regions. Let $p_{j}$ be the equilibrium price of good $j(j=1,2)$ and $w_{i}^{k}$ be the price of factor $k$ ( $k=n$ (unskilled), $e$ (educated)) in region $i$. In each region and for both goods, price equals unit cost. Thus,

$$
p_{1}=c_{1}\left(w_{i}^{n}, w_{i}^{e}\right) \quad p_{2}=c_{2}\left(w_{i}^{n}, w_{i}^{e}\right)
$$


November 8, 1997

for both regions. This pair of equations provides the same two equations in the unskilled and educated wages for both regions, and hence the unskilled wage is the same in both regions and so too is the skilled wage. An essential feature of the spatial mismatch hypothesis is that unskilled black workers downtown have an incentive to commute to the suburbs for betterpaying jobs. But with factor price equalization, this incentive vanishes. Thus, examination of the spatial mismatch hypothesis requires a model in which factor price equalization between downtown and suburbia does not occur. There are several ways to avoid factor price equalization. It does not occur if either: a) the two regions have access to different technologies; b) the number of factors exceeds the number of goods, which with two goods would require at least three factors; c) specialization occurs; or d) one or more of the goods is costly to transport.

The way factor price equalization is avoided here is to assume that one of the domestically-produced goods is non-tradable. The non-tradable domestically-produced good is called services; these are low-tech services such as fast food, laundry, home improvements, and domestic services, as well as the structure component of housing. The tradable domestically produced good, called the home good, covers high-tech manufacturing and services, including both computer hardware and software for example. A foreign good is inserted to account for changes that have occurred between the domestic economy and the rest of the world. The foreign good covers low-tech manufactures such as clothing and food. This categorization of goods is imperfect but permits examination of the effects of almost all the exogenous changes noted earlier affecting suburbanization and the market for unskilled labor. Thus:

- A.10 (domestic goods) There are two domestically-produced goods. Services are produced with skilled and unskilled domestic labor using the same technology downtown and in the suburbs, and are non-tradable. The tradable home good is produced with a more skilled-labor-intensive technology that is again common to downtown and suburbia.

- A.11 (foreign good) There is a single foreign good. 
November 8, 1997

Several of the exogenous factors listed earlier — the reduction in trade restrictions and in shipping costs between the domestic economy and the rest of the world - relate to changes in the ratio of the domestic to the "world" price of traded goods. Account of these factors is taken as follows: A fictitious international marketplace is assumed where the foreign good and the home good are exchanged. The foreign good at this international marketplace is taken as the numéraire $\left(\bar{p}^{f}=1\right)$. The price of the home good at this marketplace — its "world price" — is taken as exogenous, $\bar{p}^{h}$. The downtown and suburban prices of the foreign good ( $\bar{p}_{1}^{f}$ and $\bar{p}_{2}^{f}$, respectively) exceed its world price by the cost of shipping the foreign good from the international market place. Since the cost of shipping this good to downtown exceeds the cost of shipping it to suburbia, $\bar{p}_{1}^{f}>\bar{p}_{2}^{f}>1$. Also because of transport costs, the downtown and suburban prices of the home good fall short of the world price: $\bar{p}_{1}^{h}<\bar{p}_{2}^{h}<\bar{p}^{h}$.

Thus:

- A.12 (fixed world prices) With the foreign good at the international marketplace as numéraire, the world price of the home good is fixed at $\bar{p}^{h}$.

- A.13 (goods transport costs) As a result of transport costs, the domestic prices of the home and foreign goods satisfy the above inequalities.

The above assumptions provide a complete description of the production and transport technologies. All that is left is to describe tastes and land ownership.

- A.14 (tastes) All workers have identical tastes described by a conventional utility function with land, the home good, services, and the foreign good as arguments. ${ }^{16}$

The treatment of land ownership is always problematical. Since the focus is on lowskilled workers who are predominantly renters, it is assumed that:

- A.15 (land ownership) Land ownership is external.

This detailed presentation of assumptions has been instructive in indicating how

\footnotetext{
16 Note that preferences for the racial composition of the neighborhood are treated only implicitly, by assuming complete segregation in housing.
} 
November 8, 1997

difficult it is to construct a persuasive model of the spatial mismatch hypothesis, and suggests why the literature on the hypothesis has to date been almost exclusively empirical.

\section{II.2 Mathematical statement of the model}

Notation:

\begin{tabular}{|c|c|}
\hline$i$ & index of islands ( $i=1$, downtown; $=2$, suburbia) \\
\hline$j$ & $\begin{array}{l}\text { index of produced goods }(j=f, \text { foreign good; }=h \text {, home good; } \\
=s \text {, services ) }\end{array}$ \\
\hline$k$ & index of skill type ( $k=n$, unskilled; $=e$, educated or skilled) \\
\hline$B, B^{k}, B_{i}^{k}$ & $\begin{array}{l}\text { number of black workers, number of black workers of skill type } k, \text { number of } \\
\text { black workers of skill type } k \text { who work on island } i\end{array}$ \\
\hline$W, W^{k}, W_{i}^{k}$ & corresponding variables for white workers \\
\hline$R_{i}$ & land rent on island $i$ \\
\hline$p_{i}^{j}$ & price of good $j$ on island $i$ \\
\hline$w_{i}^{k}$ & the wage of $k$-type labor on island $i$ \\
\hline $1-\beta$ & the proportion of the wage that is lost in commuting \\
\hline $\bar{A}_{i}$ & land area of island $i$ \\
\hline
\end{tabular}

This is the basic notation. Other notation will be introduced later.

There are four cases to treat: no commuting occurs, some unskilled black workers commute to the suburbs but no skilled white workers commute downtown, etc. Since the aim is to illustrate the workings of the model rather than to provide an exhaustive examination of it, only one case is treated here: that where some unskilled black workers commute to the suburbs, but no skilled white workers commute downtown.

The model is a variant of familiar models from international trade theory. The usual procedure in working with such models is to employ demand and unit cost functions, which are functions only of prices. The only endogenous quantity variable that enters the analysis is $B_{1}^{n}$. Since $\bar{p}_{1}^{f}, \bar{p}_{2}^{f}, \bar{p}_{1}^{h}$, and $\bar{p}_{2}^{h}$ are exogenous to the model, the endogenous variables are $w_{1}^{n}, w_{2}^{n}, w_{1}^{e}, w_{2}^{e}, p_{1}^{s}, p_{2}^{s}, R_{1}, R_{2}$ and $B_{1}^{n}:$ the wages, services prices, and land rents, both downtown and in the suburbs, as well as $B_{1}^{n}$. Since there is a numéraire good, nine equations will be needed to characterize equilibrium.

- Equalization of the net-of-commuting cost wages of unskilled black workers downtown and 
November 8, 1997

in the suburbs

$$
\frac{w_{1}^{n}}{\bar{p}_{1}^{h}}-\beta \frac{w_{2}^{n}}{\bar{p}_{2}^{h}}=0
$$

An unskilled black worker who works in the suburbs is paid $w_{2}^{n}$. This translates into $w_{2}^{n} / \bar{p}_{2}^{h}$ units of the home good. Since a proportion $1-\beta$ of this is used up in his commute, he arrives downtown with $\beta w_{2}^{n} / \bar{p}_{2}^{h}$ units. Meanwhile, an unskilled black worker who works downtown is paid $w_{1}^{n} / \bar{p}_{1}^{h}$ in home goods. These must be equal in equilibrium.

- Market-clearing in the land markets

Each worker maximizes his utility subject to his budget constraint. From this his demand functions can be derived, which are functions only of his wage and the price of goods on the island on which he resides. Since workers have identical tastes, they all have the same form of demand functions. Let $\ell(\cdot)$ denote a worker's lot or land demand function. Then the lot demand for an unskilled black worker is $\ell_{1}^{n}=\ell\left(\bar{p}_{1}^{h}, \bar{p}_{1}^{f}, p_{1}^{s}, R_{1}, w_{1}^{n}\right)$, and for all unskilled black workers is $B^{n}$ times this demand. The lot demand by black workers must equal the supply of land downtown. Thus,

$$
\ell\left(\bar{p}_{1}^{h}, \bar{p}_{1}^{f}, p_{1}^{s}, R_{1}, w_{1}^{n}\right) B^{n}+\ell\left(\bar{p}_{1}^{h}, \bar{p}_{1}^{f}, p_{1}^{s}, R_{1}, w_{1}^{e}\right) B^{e}=\bar{A}_{1}
$$

The analogous equation for white workers is

$$
\ell\left(\bar{p}_{2}^{h}, \bar{p}_{2}^{f}, p_{2}^{s}, R_{2}, w_{2}^{n}\right) W^{n}+\ell\left(\bar{p}_{2}^{h}, \bar{p}_{2}^{f}, p_{2}^{s}, R_{2}, w_{2}^{e}\right) W^{e}=\bar{A}_{2}
$$

\section{- Price equals unit cost in home goods production}

Given factor prices downtown, the least cost way of producing a unit of home good there can be solved for: $c_{1}^{h}=c^{h}\left(w_{1}^{n}, w_{1}^{e}\right)$. Competition among downtown home goods producers pushes price down to unit cost, Thus,

$$
c^{h}\left(w_{l}^{n}, w_{l}^{e}\right)=\bar{p}_{1}^{h}
$$

and similarly for the suburbs: 
November 8, 1997

$$
c^{h}\left(w_{2}^{n}, w_{2}^{e}\right)=\bar{p}_{2}^{h}
$$

- Price equals unit cost in service production

$$
\begin{aligned}
& c^{s}\left(w_{1}^{n}, w_{1}^{e}\right)=p_{1}^{s} \\
& c^{s}\left(w_{2}^{n}, w_{2}^{e}\right)=p_{2}^{s}
\end{aligned}
$$

The remaining equilibrium conditions entail labor market clearing. Start with the downtown market for skilled labor:

demand for skilled labor in downtown service production + demand for skilled labor in downtown home goods production = supply of downtown skilled labor

Where $s(\cdot)$ is the service demand function, the demand for skilled labor in downtown service production equals the demand for downtown services $B^{n} s\left(\bar{p}_{1}^{h}, \bar{p}_{1}^{f}, p_{1}^{s}, R_{1}, w_{1}^{n}\right)+$ $B^{e} s\left(\bar{p}_{1}^{h}, \bar{p}_{1}^{f}, p_{1}^{s}, R_{1}, w_{1}^{e}\right)$ times the demand for skilled labor per unit of downtown service output. The latter is termed the unit factor demand for skilled labor in downtown service production ${ }^{17}$ and is denoted as $c_{1}^{s, e}=c^{s, e}\left(w_{l}^{n}, w_{l}^{e}\right)$. Thus, the demand for skilled labor in downtown services is $\left[B^{n} s_{1}^{n}+B^{e} s_{1}^{e}\right] c_{1}^{s, e}$ using obvious notation. The demand for skilled labor in downtown home goods production is more complicated to compute since, first, home goods are used to pay land rent to external landowners as well as for foreign goods, and, second, unskilled blacks who work in the suburbs are paid in terms of suburban home goods, part of which are used up in commuting. It will be useful to do some accounting:

$$
\text { domestic production }=\text { domestic consumption }- \text { imports }+ \text { exports. }
$$

Domestic consumption equals $B^{n} h_{1}^{n}+B^{e} h_{1}^{e}$, where $h_{1}^{n}$ denotes the demand for home goods by an unskilled black worker, etc. Imports equal $B_{2}^{n} \beta\left(w_{2}^{n} / \bar{p}_{2}^{h}\right)=\left(B^{n}-B_{1}^{n}\right)\left(w_{1}^{n} / \bar{p}_{1}^{h}\right)$ (using (1)). And exports equal $\frac{R_{1}}{\bar{p}_{l}^{h}} \bar{A}_{l}+\left(B^{n} f_{l}^{n}+B^{e} f_{l}^{e}\right) \frac{\bar{p}_{l}^{f}}{\bar{p}_{l}^{h}}$ where $f_{1}^{n}$ denotes demand for the

\footnotetext{
${ }^{17}$ It equals the partial derivative of the unit cost function for downtown service production with respect to the skilled wage downtown.
} 
November 8, 1997

foreign good by an unskilled black worker, etc. The demand for skilled labor in downtown home goods production equals the downtown demand for home goods times the unit factor demand for skilled labor in downtown home goods production, $c_{1}^{h, e}$. Pulling all this together, we have:

$$
\left[B^{n} s_{1}^{n}+B^{e} s_{1}^{e}\right] c_{1}^{s, e}+\left[B^{n} h_{1}^{n}+B^{e} h_{1}^{e}-\left(B^{n}-B_{1}^{n}\right) \frac{w_{1}^{n}}{\bar{p}_{1}^{h}}+\frac{R_{1}}{\bar{p}_{1}^{h}} \bar{A}_{1}+\left(B^{n} f_{1}^{n}+B^{e} f_{1}^{e}\right) \frac{\bar{p}_{1}^{f}}{\bar{p}_{1}^{h}}\right] c_{1}^{h, e}=B^{e}
$$

It can be shown that the previous equations imply market clearing in the downtown market for unskilled labor too. The remaining equation (9) is the analog to (8) but for skilled white workers. This equation and the previous equations imply market clearing in the suburban market for unskilled labor.

\section{II.3 Interpretation}

This system of equations appears fairly intimidating. But a recursiveness in the structure permits an intuitive condensation to two equations in two unknowns. Fix $w_{1}^{n} \cdot w_{2}^{n}$ is then obtained from (1), $w_{1}^{e}$, from (4), and $w_{2}^{e}$ from (5). $p_{1}^{s}$ and $p_{2}^{s}$ are then determined from (6) and (7). Then from (2) and (3), $R_{1}$ and $R_{2}$ are determined. Having solved for all prices as a function of $w_{1}^{n}$, one can then solve for all demands as a function of $w_{1}^{n}$. Also, having determined factor prices as a function of $w_{1}^{n}$, unit factor demands as a function of $w_{1}^{n}$ can be calculated. Substituting these relationships into (8) and (9) yields two equations in two unknowns, $w_{1}^{n}$ and $B_{1}^{n}$ : (I) and (II). Eq. (I) characterizes market clearing for downtown labor and eq. (II) the same for suburban labor.

Consider first eq. (I) . Raise $w_{1}^{n}$. This causes $w_{1}^{e}$ to fall ((4)) and $p_{1}^{s}$ to rise since nontraded services are unskilled-labor-intensive ((6)). The wage changes induce a factor substitution effect away from unskilled downtown labor towards skilled downtown labor. The rise in $p_{1}^{s}$ induces an output effect away from services and towards home goods, which, since services are relatively unskilled-labor-intensive, further reduces the demand for unskilled 
November 8, 1997

downtown labor. Finally, there is a redistribution effect from skilled to unskilled downtown labor. If unskilled laborers spend a significantly larger proportion of their budgets on services than do skilled laborers, it is possible that the rise in $w_{1}^{n}$ causes the derived demand for unskilled labor downtown to increase. But in the normal case the former two effects dominate. Then for (I) to continue to hold, $B_{1}^{n}$ must fall, and so $w_{1}^{n}$ and $B_{1}^{n}$ are negatively related. Next consider eq. (II). The rise in $w_{1}^{n}$ induces a rise in $w_{2}^{n}((1))$, which induces a fall in $w_{2}^{e}((5))$ and a rise in the price of suburban services $((7))$. The normal result is a decrease in the demand for suburban unskilled labor. In this case, for (II) to continue to be satisfied, $B_{1}^{n}$ must rise, and so $w_{1}^{n}$ and $B_{1}^{n}$ are positively related in (II). These results are plotted in Figure 1.

\section{INSERT FIGURE 1}

A sample comparative static exercise is now performed informally to give some insight into the economics of the model: the effects of an increase in the population of skilled white workers, $W^{e}$. This has no effect on (I), but causes (II) to shift to the left, which causes the downtown wage of unskilled workers to rise and the number of unskilled blacks working downtown to fall. The increase in $W^{e}$, holding $w_{1}^{n}$ (and hence $w_{1}^{e}, w_{2}^{n}, w_{2}^{e}, p_{1}^{s}$, and $p_{2}^{s}$ ) constant, causes an increase in the derived demand for unskilled workers in the suburbs. To satisfy (II), a decrease in $B_{1}^{n}$ is required, which by (I) requires an increase in $w_{1}^{n}$. Intuitively, the increase in the population of skilled white workers raises the ratio of skilled to unskilled workers in the economy, which causes the wage of unskilled workers to rise. Downtown this causes a substitution away from unskilled workers. These displaced workers are then absorbed by the suburban labor market.

The model achieves a nice balance between richness and tractability/comprehensibility. Though moderately complex, its behavior is quite easy to understand because it is a variant of the very familiar 2 (goods) x 2 (factors) x 2 (regions) model of international trade theory. Its richness is evident from its wide array of exogenous parameters: $B^{n}, B^{e}, W^{n}, W^{e}, \overline{A_{1}}, \overline{A_{2}}$, $\bar{p}_{1}^{h}, \bar{p}_{2}^{h}, \bar{p}_{1}^{f}, \bar{p}_{2}^{f}$, as well as parameters characterizing the production functions for the domestic 
November 8, 1997

goods and the demand functions. This permits examination of the effects of a broad range of exogenous changes pertinent to the spatial mismatch hypothesis, including almost all those listed earlier as contributing to post-World-War-II suburbanization or the deteriorating labor market situation of unskilled blacks. For example, the lowering of domestic trade barriers can be represented as reductions in $\bar{p}_{1}^{f}$ and $\bar{p}_{2}^{f}$ (and the lowering of foreign trade barriers by rises in $\bar{p}_{1}^{h}$ and $\bar{p}_{2}^{h}$ ); the reduction in the costs of shipping from the suburbs to the rest of the world due to improvements in trucking and the inter-state highway systems, as a rise in $\bar{p}_{2}^{h}$; the computer revolution, as an increase in a parameter characterizing the efficiency of skilled labor; and so on.

How should the spatial mismatch hypothesis be interpreted in the context of the model? Does a "dispersal of jobs" mean that the number of unskilled jobs downtown falls absolutely, or relative to the total number of unskilled jobs, or relative to the total number of jobs? Also, does "low earnings of Afro-American workers" entail an absolute or only a relative fall in the downtown wage of unskilled workers? The hypothesis refers to the housing market but what does it implicitly assume about the determination of housing rents? Is it an implication of the hypothesis that downtown unskilled workers become absolutely worse off? Finally, how is unemployment to be treated? Consider the last question first. Unemployment can be treated by imposing a minimum wage. Since the unskilled wage is higher in the suburbs because of commuting costs, it appears possible for the minimum wage to bind downtown but not in the suburbs. With potential unemployment, the issue arises as to how to specify the commuting equilibrium condition. It is reasonable to assume that unemployed, unskilled black workers will take a job in the suburbs even if the net-of-commuting cost real wage is less than the minimum wage, since the alternative is unemployment. But with this assumption, unemployment occurs only if the minimum wage is binding both downtown and in the suburbs. A minimum wage will not be formally treated here. But to do so is an important extension. The difficulty in answering the other questions points to another problem with the spatial mismatch hypothesis: the hypothesis is vague, imprecise, and ambiguous in important 
November 8, 1997

respects. Hopefully, this paper will encourage the formulation and testing of more precise hypotheses.

Full-blown comparative static analysis of the model is complex, and understandably so given the model's richness. In consequence, a thorough analysis shall not be provided here; that will be left for a subsequent paper. ${ }^{18}$ Instead, a numerical example will be examined.

\section{II.4 Numerical example}

The base case parameters are:

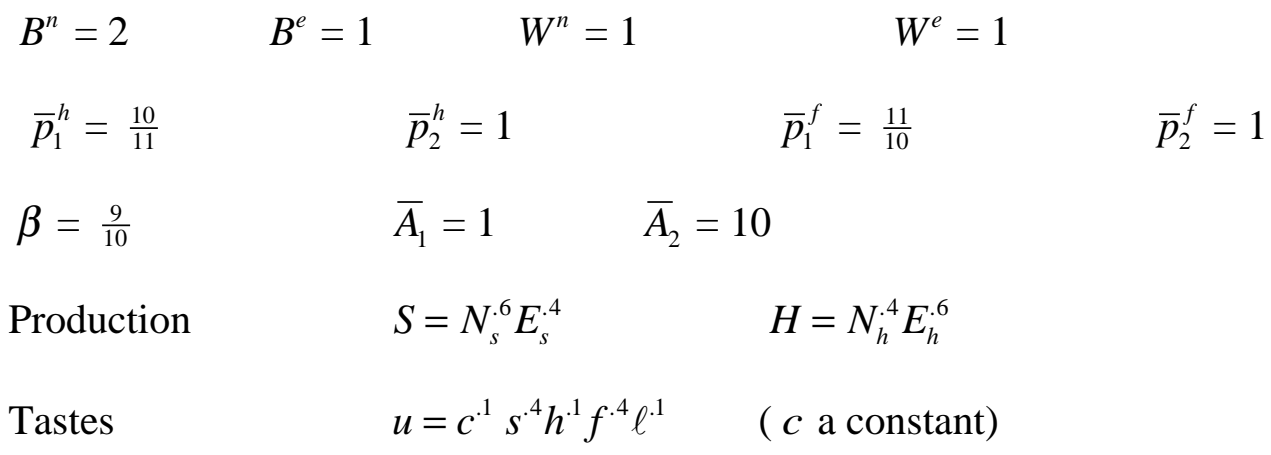

where $S$ is output of services, $N_{s}$ the number of unskilled workers in service production, $E_{s}$ the number of skilled workers in service production, etc.

Several comments are in order. First, in keeping with A.8, the ratio of unskilled to skilled workers is higher for blacks than for whites; second, in keeping with A.9, downtown is more crowded than suburbia, having a smaller land area and a larger population; third, $\bar{p}_{1}^{h}<\bar{p}_{2}^{h}$ captures the higher cost of transporting goods outside the city from downtown rather than from the suburbs; fourth, $\bar{p}_{1}^{f}>\bar{p}_{2}^{f}$ for the same reason; fifth, untraded services are

\footnotetext{
18 The comparative-static properties of the model can be derived in a particularly useful and insightful form using the Jones' hat procedure (Jones (1965)), as presented and adapted in Atkinson and Stiglitz (1980). This procedure entails logarithmic differentiation of the entire system of equations characterizing equilibrium: (1) - (9); for example, (1) becomes

$$
\hat{w}_{1}^{n}-\hat{w}_{2}^{n}=\hat{\bar{p}}_{1}^{h}-\hat{\bar{p}}_{2}^{h}+\hat{\beta},
$$

where $\hat{x} \equiv \frac{d x}{x}$. The advantage of this procedure is that all comparative static results are expressed in terms of elasticities and shares, all of which are unitless and correspond to familiar and measurable quantities. The demand side parameters which appear are own- and cross-price elasticities, income elasticities, and expenditure shares; the supply-side parameters, elasticities of substitution, and value and physical factor shares.

A companion paper will present the formal comparative-static analysis, which is algebra-intensive, and employ it to provide a more comprehensive discussion of the comparative-static properties of the model. That paper will also examine the existence, uniqueness, and stability of equilibrium, and the complications which arise when local agglomerative economies of scale are taken into account.
} 
unskilled-labor-intensive relative to traded, home-produced goods; and sixth, the expenditure shares on services, home goods, imported goods, and land are .4, .1, .4, and .1, respectively, independent of income, location, or race.

Substitution of these parameters and functions into (1) - (9) yields

$$
\begin{aligned}
& w_{1}^{n}=\frac{9}{11} w_{2}^{n} \\
& 2 w_{1}^{n}+w_{1}^{e}=10 R_{1} \\
& w_{2}^{n}+w_{2}^{e}=100 R_{2} \\
& \ln \left(\frac{10}{11}\right)=.4 \ln w_{1}^{n}+.6 \ln w_{1}^{e}+c_{0}\left(c_{0}=-\ln (.4)^{.4}(.6)^{.6}\right) \\
& 0=.4 \ln w_{2}^{n}+.6 \ln w_{2}^{e}+c_{0} \\
& \ln p_{1}^{s}=.6 \ln w_{1}^{n}+.4 \ln w_{1}^{e}+c_{0} \\
& \ln p_{2}^{s}=.6 \ln w_{2}^{n}+.4 \ln w_{2}^{e}+c_{0} \\
& .16+.48 \frac{w_{1}^{e}}{w_{1}^{n}}=.6 B_{1}^{n} \\
& 1.72-.48 \frac{w_{2}^{e}}{w_{2}^{n}}=.6 B_{1}^{n}
\end{aligned}
$$

The solution of this system of equations is given in column the base case of Table 1 , where $u_{1}^{n}$ denotes the utility of unskilled downtown residents. Because of commuting costs along with an untraded good, factor price equalization does not occur. For these reasons and also because the proportion of workers who are unskilled is higher for blacks than for whites, production of home goods is more unskilled-labor-intensive downtown than in the suburbs, and likewise for service production. Thus, the ratio of the unskilled to the skilled wage is lower downtown than in the suburbs.

\section{INSERT TABLE 1}

The change considered is a decrease in $\beta$ from $\frac{9}{10}$ to $\frac{8}{10}$. This may be interpreted as an increase in the difficulty unskilled black workers have in commuting to the suburbs. The only change this causes is that $\left(1^{*}\right)$ becomes $w_{1}^{n}=\frac{8}{11} w_{2}^{n}$. As a result of the increased cost of 
November 8, 1997

commuting, fewer unskilled blacks work in the suburbs. The unskilled-labor-intensity of downtown production increases, which depresses the downtown unskilled wage and raises the downtown skilled wage. Since services are relatively unskilled-labor-intensive, the price of services falls. Opposite changes occur in the suburbs.

\section{II.5 Concluding observations}

There is no unambiguously right model to address a particular issue. Different models cast light on different facets. Nevertheless, the model discussed in this section seems wellsuited for examining the spatial mismatch hypothesis. It achieves a nice balance between richness and tractability; it is (quasi-) general equilibrium and therefore suitable for welfare analysis; it is capable of addressing most of the themes raised in the literature on the spatial mismatch hypothesis, as well as many raised in the broader literature on the causes of increased inequality between skilled and unskilled workers, on the economic status of the black underclass, and on the economic plight of many U.S. central cities; and there is scope for enrichment of the model.

We now expand on this last point. One simplification made in the model is to treat downtown as one island and the suburbs as another. One could extend the model to treat differentiated space explicitly, as is done in Brueckner and Martin (1995). An alternative is to assume that the commuting cost of the marginal unskilled black who works in the suburbs is

increasing in the number of commuters, i.e. $\beta=\beta\left(B^{n}-B_{1}^{n}\right), \beta^{\prime}<0$. An unappealing aspect of the model in its current form is that all land is owned externally. Incorporating internal ownership of land mechanically is straightforward — one simply assigns ownership shares. But to do so in an economically interesting way requires treating the tenure choice decision, which is far from trivial. Another unappealing aspect of the model is the absence of a public sector. In the context of the spatial mismatch hypothesis, the public sector is important in at least three respects. First, the public sector provides public infrastructure which is an input into production. One possible reason for the suburbanization of jobs is the failure of central city governments to provide adequate public infrastructure, especially urban roads. Second, 
November 8, 1997

public services enter the utility function. The quality of public education appears to be a particularly important determinant of household location, with the recent literature suggesting that educational quality depends as much on the classroom peer group as on the level of expenditure per student. ${ }^{19}$ Third, particularly with the ongoing devolution of social assistance, differences among local governments in the generosity of their social assistance is likely to become increasingly important in the locational choice of poor households. Each of these elements could be incorporated into the model. To keep the model as simple as possible, it was assumed that the only commuting which occurs is by downtown unskilled black workers to the suburbs. Commuting by whites from the suburbs to jobs downtown remains important in most U.S. cities. The model can be extended straightforwardly to treat this.

Another deficiency of the model is that it takes household location by race as given and assumes complete housing segregation. But in fact household location by race is continually changing. Furthermore, in many cities there has been significant suburbanization of middleclass blacks, which reflects changes in the nature of housing market discrimination and presumably therefore racial attitudes. To address these issues satisfactorily requires endogenizing the pattern of household location by race, starting from a specification of racial housing preferences, which has already been done in several urban models (e.g., Courant and Yinger (1977)). A related deficiency of the model is that it ignores labor market discrimination. It is hard to believe, however, that racial preferences sufficiently strong to explain the extreme pattern of housing segregation by race observed in most U.S. cities do not translate into labor market discrimination.

The model should also be extended to incorporate agglomerative economies of scale. Any exogenous change that causes job suburbanization will then increase the productivity of suburban labor and decrease that of downtown labor. Furthermore, the nonconvexities in production caused by such scale economies may lead to multiple equilibria and catastrophic (in

\footnotetext{
${ }^{19}$ The perceived crime level is another important factor in the household location decision. Accordingly, expenditure on crime prevention is important. How to model the determinants of the level of crime is problematical.
} 
November 8, 1997

the sense of catastrophe theory) transitions between equilibria.

Perhaps the greatest weakness of the model is its failure to address informational aspects of the spatial mismatch hypothesis. The model could perhaps be extended for this purpose, but the extended model would be excessively cumbersome. Altogether different models which put search, vacancies, and unemployment at center stage would be more suitable, such as those in the papers by Coulson et al. (1997), Zenou and Smith (1995), Wasmer and Zenou (1997), and Smith and Zenou (1997). Search models have the advantage that they treat the search process explicitly, but are analytically difficult. Matching models which generate equilibrium wages, vacancies, and unemployment with a minimum of algebraic fuss, provide a promising alternative. Extending existing search and matching models to treat how people search over space poses a challenge.

\section{Concluding Remarks}

This paper started with several observations concerning the spatial mismatch hypothesis. One was that the hypothesis asserts a causal link between endogenous variables the suburbanization of jobs (in the presence of housing segregation/discrimination) and the poor labor market status of blacks. The hypothesis has certainly been useful in stimulating a large amount of empirical work on racial aspects of urban labor markets, but is conceptually flawed. It should be replaced by alternative hypotheses concerning what exogenous factors might have combined to give rise simultaneously to the suburbanization of jobs and the immiserization of inner-city blacks. And to be conceptually sound, these alternative hypotheses should be based on general equilibrium models of the urban economy, which account for the interaction between housing and labor markets, among other things. A second, related observation was that, with the exception of a very few recent papers, the literature on the spatial mismatch hypothesis has been entirely empirical. Further theoretical work is needed not only to strengthen the conceptual basis of the hypothesis, but also to guide econometric specification and to provide a normative framework for policy prescription. 
November 8, 1997

Prompted by these observations, my aim in writing this paper was to develop an illustrative general equilibrium, spatial model of urban labor markets, incorporating race, that might serve as a conceptual basis for examining the spatial mismatch hypothesis.

The paper did not provide a complete analysis of the model; that will be done in a subsequent, more technical paper. Rather it introduced the economics of the model and illustrated how the model can be applied to cast light on racial aspects of urban labor markets, including the spatial mismatch hypothesis. It is hoped that this paper will strengthen the theoretical foundations of empirical work related to the spatial mismatch hypothesis, and will encourage empirical researchers to formulate and test more precise, causal hypotheses. More generally, it is hoped that the paper will stimulate further theoretical work on spatial and racial aspects of urban labor markets, which have not been given the attention their importance merits. 
November 8, 1997

\section{BIBLIOGRAPHY}

Arnott, R. 1996. "Economic theory and the spatial mismatch hypothesis". Mimeo.

Atkinson, A., and J. Stiglitz. 1980. Lectures on Public Economics. New York: McGrawHill.

Becker, G.S. 1971. The Economics of Discrimination, 2nd. edition. Chicago: University of Chicago Press.

Bénabou, R. 1996. "Equity and efficiency in human capital investment: the local connection." Review of Economic Studies 63, 237-264.

Bound, J., and R. Freeman. 1992. "What went wrong? The erosion of relative earnings and employment among black men in the 1980s." Quarterly Journal of Economics 107, 201-232.

Bound, J. and H. Holzer. 1991. "Industrial shifts, skill levels, and the labor market for white and black males." National Bureau of Economic Research Working Paper No. 3715.

Brueckner, J. and R. Martin. 1995. "Spatial mismatch: an equilibrium analysis." Unpublished paper.

Castells, M. 1985. "High technology, economic restructuring and the urban regional process in the U.S." in M. Castells, ed., High Technology, Space and Society. Beverly Hills, CA: Sage Publications.

Caves, R., and R. Jones. 1977. World Trade and Payments. Boston: Little, Brown.

Chipman, J.S. 1970. "External economies of scale and competitive equilibrium." Quarterly Journal of Economics 84, 347-385.

Coulson, N.E., D. Laing, and P. Wang. 1997. "Spatial mismatch in search equilibrium." Mimeo.

Courant, P. and J. Yinger. 1977. "On models of racial prejudice and urban residential structure." Journal of Urban Economics 4, 272-291.

Ellwood, D. 1981. "The mismatch hypothesis: are there teenage jobs missing in the getto." Unpublished. Ph.D. dissertation, Harvard University. 
November 8, 1997

Henderson, J.V. 1988. Urban Development: Theory, Fact, and Illusion. Oxford: Oxford University Press.

Holzer, H. 1987. "Informal job search and black youth unemployment." American Economic Review 77, 446-452.

Holzer, H. 1988. "Search method use by unemployed youth." Journal of Labor Economics 6, 1-20.

Holzer, H., K. Ihlanfeldt, and D. Sjoquist. 1994. "Work, search and travel among white and black youth." Journal of Urban Economics 35, 320-345.

Ihlanfeldt, J., and D. Sjoquist. 1989. "The impact of decentralization on the economic welfare of central city blacks." Journal of Urban Economics 26, 110-130.

Ihlanfeldt, J., and D. Sjoquist. 1990. "Job accessibility and racial differences in youth employment rates." American Economic Review 80, 267-276.

Ihlanfeldt, K., and D. Sjoquist. 1991. "The effect of job access on black and white youth employment: a cross sectional analysis." Urban Studies 28, 255-265.

Jencks, C., and S. Mayer. 1989. "Residential segregation, job proximity and black job opportunities" in M. McGeary and L. Lynn, eds., Inner-City Poverty in the United States. Washington, D.C.: National Academy Press.

Jones, R. 1965. "The structure of simple general equilibrium models." Journal of Political Economy 73, 557-572.

Kain, J. 1968. "Housing segregation, Negro employment, and metropolitan decentralization." Quarterly Journal of Economics 82, 175-197.

Kain, J. 1994. "The spatial mismatch hypothesis: three decades later." Housing Policy Debate 3, 371-462.

Kasarda, J. 1989. "Urban industrial transition and the underclass." The Annals of the American Academy of Political and Social Science 501, 26-47.

Krugman, P. 1991. "Increasing returns and economic geography." Journal of Political Economy 99, 483-499. 
November 8, 1997

Millis, E. 1972. Studies in the structure of the urban economy. Baltimore: The Johns Hopkins Press.

O'Regan, K. and J. Quigley. 1993. "Family networks and youth access to jobs." Journal of Urban Economics 34, 230-248.

O'Regan, K. and J. Quigley. 1996. "Where youth live: economic effects on employment prospects." Mimeo.

O'Regan, K. and J. Quigley. 1997. "Accessibility and economic opportunity." Mimeo.

Sah, R. 1991. "Social osmosis and patterns of crime." Journal of Political Economy 99, 12721295.

Smith, T. and Y. Zenou. 1997. "Dual labour markets, urban unemployment and multicentric cities." CEPR discussion paper 1566.

Turner, M. 1992. "Discrimination in urban housing markets: lessons from fair housing audits." Housing Policy Debate 3, 185-215.

Wasmer, E. and Y. Zenou. 1997. "Equilibrium urban unemployment." Mimeo.

Wilson, W. 1987. The Truly Disadvantaged. Chicago: University of Chicago Press.

Yinger, J. 1986. "Measuring racial discrimination with fair housing audits: caught in the act." American Economic Review 76, 881-893.

Zenou, Y. and T. Smith. 1995. "Efficiency wages, involuntary unemployment and urban spatial structure." Regional Science and Urban Economics 25, 547-573. 


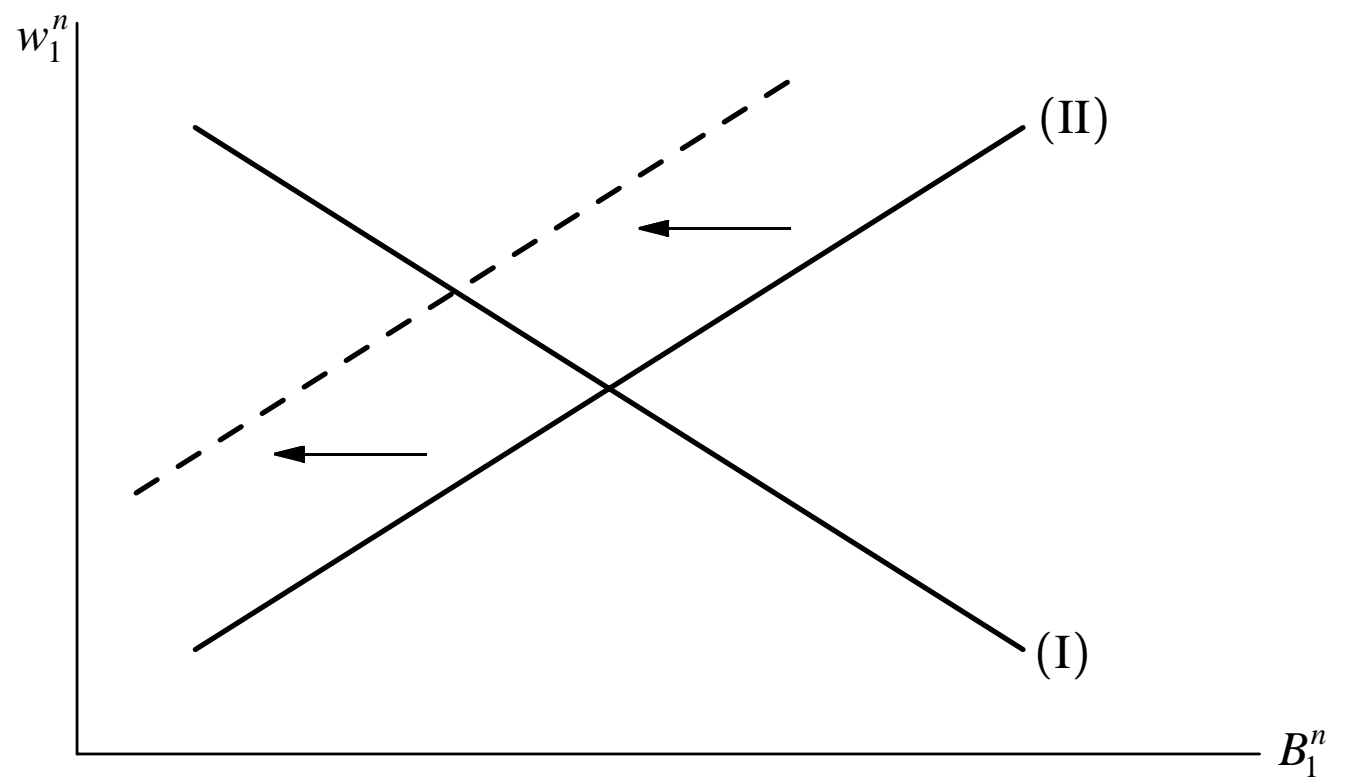

Figure 1: Equilibrium: The Normal Case. 
Table 1: Numerical Example

\begin{tabular}{|c||c|c|} 
& Base case & $\beta=.8$ \\
\hline \hline$w_{1}^{n}$ & .329560 & .313209 \\
$w_{1}^{e}$ & .582435 & .602532 \\
$w_{2}^{n}$ & .402795 & .430663 \\
$w_{2}^{e}$ & .597221 & .571171 \\
$R_{1}$ & .124155 & .122896 \\
$R_{2}$ & .01000 & .010018 \\
$p_{1}^{s}$ & .811231 & .797587 \\
$p_{2}^{s}$ & .924251 & .945092 \\
$B_{1}^{n}$ & 1.680514 & 1.80566 \\
$u_{1}^{n}$ & 1 & .957833 \\
\hline
\end{tabular}

